Series Lines in Spark Spectra.-In the issue of this journal for April 9 of the present year (vol. xciii., p. 145) a summary was given of the Bakerian lecture delivered by Prof. Fowler on April 2 on series lines in spark spectra. Attention is directed to the fact that this lecture is now published in the Philisophical Transactions of the Royal Society (Series A, vol. ccxiv., pp. 225-66), and is accompanied by some excellent reproductions from photographs of the spectrum of the magnesium arc in vacuo, the various series of arc and enhanced lines being clearly indicated.

A Brilliant Fireball.-Mr. W. F. Denning writes : "On November II, at II.I3 p.m., a magnificent meteor was seen from near Purley, Surrey, Stowmarket, Hornsey, and other places. It looked like an unusually large ball from a Roman candle firework, and moved very slowly in the north-east sky, occupying about $6 \mathrm{sec}$. in an extended course. It was not a Leonid, but apparently from a radiant near a Lyræ in the north-west. The meteor illumined the sky vividly for several seconds, and was evidently rather near the earth's surface. From a preliminary discussion of the few descriptions already to hand it appears that the object fell from a height of fifty to thirty-two miles, and its velocity was about eleven miles a second. There is no known shower near Vega at the middle of November, but certain large meteors appear to be isolated. Some of the observers supposed it to have been one of the regular November meteors, but its direction was different and its speed altogether too slow for it to have been a Leonid.'

Measured Parallaxes Summarised.--A reprint from the Astronomische Nachrichten, No. 4754, has been received, and it contains a communication on measured parallaxes summarised by $\mathrm{Mr}$. O. R. Walkey. The author states that in view of the inherent uncertainty of all measured parallaxes, it does not seem profitable to enter into a detailed discussion of the individual results, but instead the results are summarised in a series of tables of distance and consequent luminosities and cross-motions speeds according to the spectral type. The tables given represent $52 \mathrm{I}$ stellar systems, not counting the sun. The first three tables do not include the Hyades group, which consists mainly of first-type stars; these are dealt with in a fourth table according to their component spectral classes. The investigation is one that is the result of a large amount of labour, and the essence of the work lies in the tables, which will no doubt be carefully scrutinised by those to whom the subject is of special interest.

RePort OF THE PARIS OBSERvatoky FOR I9I3.Like all other large observatories situated in or near towns, the work of the Paris Observatory is being severely handicapped by the presence of disadvantageous observing conditions such as smoke, night glare, etc. The report for the year 1913 gives a good idea of the great number of branches of work undertaken, but in the different summaries of the recent progress there is an underlying tone of regret that much cannot be done and much that is done is not as satisfactory as it might have been owing to the present observing conditions. Monsieur Baillaud, the director, opens his report with a reference to the deplorable conditions of the actual situation and to the indispensability of the creation of a branch establishment which he advocated two years ago. With regard to the meridian work, the north and south horizons have been shut out by seven-storey buildings, and he points out how the work of the equatorials is restricted by the haze and fog in the lower strata of the atmosphere of Paris. Comet Delavan was estimated as of the eleventh magnitude at Besançon.
Bordeaux, and Lyon, while at Paris it appeared of magnitude i3. Regular photometric work, so important for the undertaking of the Carte du Ciel, is described as impossible, and in the astrophysical department the quality of the stellar images projected on the slit exercises unfortunately a very great influence on the determinations of radial velocity. Numerous other references to other branches of work effected are given, making a clear case for the necessity for an out-station. For the present, no steps can be taken, but it is hoped that in the near future Monsieur Baillaud's appeal will be considered and carried out. The annual report takes the same form as in previous years, and the work of the several departments during the past year is described in the various sections.

\section{THE FUNCTION OF THE EARTH IN RADIO-TELEGRAPHY.}

A LECTURE on the above subject was delivered A on Friday evening, November 13, by Dr. J. A. Fleming, to the members of the Wireless Society of London, at the Institution of Electrical Engineers. Dr. Fleming said that the present period of enforced inactivity for all loyal radio-telegraphists, except those engaged at the seat of war, offered an opportunity to re-consider some of the purely scientific questions involved in the art. He proposed therefore to discuss the function of the earth in radio-telegraphy. Apart from the disputed question whether the aerial wires should preferably be earthed at the base or connected to an insulated balancing capacity, it was well known that the nature of the soil or surface between the transmitting and receiving stations had a great effect on the signal strength. This effect depended much upon the wave-length. Thus Dr. L. W. Austin had shown that the ground to the north and north-east of Newport, Rhode lsland, U.S.A., exercised a powerful absorption on radio-telegraphic waves of about rooo metres wave-length. Experiments made between Brant Rock wireless station and a U.S. cruiser Birmingham, lying at Newport, showed that whereas electric waves of 3750 metres wave-length suffered little or no absorption in travelling over the 45 miles other than that due to the normal space decrease of energy, waves 1000 metres in length lost 95 per cent. of their signalling energy in passing over the same district.

Dr. Fleming first gave a brief mathematical discussion showing the manner in which the gradual penetration of an alternating current into a conductor can be explained. It is well known that high frequency electric currents are confined to a thin skin or layer of the surface of metallic wires. In the case of copper this skin has a thickness of about $0.25 \mathrm{~mm}$. for currents of a frequency of one million. In the case of iron the skin for the same frequency is about $0.02 \mathrm{~mm}$.

An elegant experiment was shown by Dr. Fleming with his cymometer to illustrate this surface flow of high-frequency currents. An oscillation circuit was arranged in which high-frequency currents were generated, and these were detected by placing alongside a cymometer having a Neon vacuum tube as a detector of secondarv oscillations in its circuit. In the primary oscillation circuit were inserted successively small spirals of copper, brass, iron, and galvanised iron; all having the same size and same number of turns. The oscillations in the cymometer circuit were indicated by the brilliant glow of the Neon tube. When the iron spiral was inserted the Neon tube did not glow, because of the damping of the oscillations caused by the energy absorbed to magnetise the iron. 
The galvanised iron spiral behaved, however, just like a copper or brass spiral, because the oscillations did not penetrate through the thin layer or skin of zinc into the iron. If, however, this zinc was oxidised or broken, then the iron core exerted its effect in damping the oscillations.

Dr. Fleming then explained that when a radiotelegraphic wave passes over the earth it penetrates to some extent into it, and also loses amplitude owing to the absorption of wave energy by the soil. The depth of penetration or depth in which the forces attenuate to $\bar{e}^{-1}$ or to 0.368 of their surface value, and the horizontal attenuation or distance in which the surface values decrease to the same fraction of their original value can be calculated as shown by Dr. Zenneck when the values of the soil conductivity, soil dielectric constant, and frequency are known. Thus taking the generally accepted values for sea water for waves $1000 \mathrm{ft}$. in wave-length, the penetration into the sea is at most about one metre. In the ordinary dry soil it may be Ioo or several hundred metres. There is a certain soil conductivity and wave-length which gives the maximum attenuation of the wave over a given distance.

The calculation of the depth of penetration and attenuation of the wave with distance can be made when this soil conductivity and dielectric constant is known. Recent researches have shown, however, that the conductivity of imperfect insulators for alternating currents is much greater than for direct currents. Dr. Fleming referred to researches by himself and $\mathrm{Mr}$. Dyke for proof of this fact. Lately, he said, Mr. Bairsto had continued this work in his laboratory for currents of extra high frequency of one or more million, and found their dielectrics had a maximum conductivity for a certain high frequency. The inference from this was that the earth was an incomparably better conductor for the high frequencv currents use 1 in radio-telegraphy than for ordinary low frequency or steady currents. Dr. Fleming then went on to consider the propagation of an electric wave over the earth's surface, and pointed out that Sommerfeld had shown that when a Hertzian oscillator had one half connected to the earth there would not only be space waves through the dielectrics (air and earth), but a surface wave along the surface which would consist in longitudinal electric currents propagated as a wave motion along the surface. Dr. Fleming pointed out that this surface wave might be the explanation of the well-known facts that signals from long distance wireless telegraph stations can be picked up and detected without any high receiving wire, merely by connecting one end of the receiver to the earth and the other to any insulated mass of metal in the interior, it may be, of a house.

Passing then to the consideration of the diffraction of long electric waves round the earth, Dr. Fleming gave a brief account of the state of the theories advanced by Poincaré, Nicholson, Macdonald, and Rybczynski. These agreed that the amplitude of an electric wave sent out horizontally from any point on the earth's surface diminished according to an exponential function of the distance and wave-length. The last-named analyst had shown that this function was of the form $e^{-0.0018 r / 3} \sqrt[3]{\lambda}$ where $r$ is the distance of the sending and receiving stations, and $\lambda$ is the wave length. Actual observations by Austin over distances up to rooo miles had led to an empirical formula differing only in that $\sqrt{\lambda}$ appears instead of $\sqrt[3]{\lambda}$

The bulk of the evidence so far collected as to long distance transmission showed, however, that true diffraction of space waves or even the surface waves could not contribute more than a moderate fraction, perhaps not 20 per cent., to the total observed result. The chief part of the effect for distances of 3000 to 4000 miles must be contributed by space waves which had reached the receiving station indirectly, that is, after reflection or refraction at the surfaces of layers of high-altitude ionised atmospheric gases in the manner explained by Heaviside and by Eccles.

The great variations in signal strength taking place from day to day in long-distance wireless intercourse proved that this must be the case.

In conclusion, Dr. Fleming exhibited a chart show. ing the variation in the strength of the signals received at University College, London, from the Eiffel Tower station in Paris at I I a.m. each day during last July, prior to the outbreak of war. The sudden falling off on certain days was remarkable. Dr. Fleming said that the further examination of the cause of these variations was one of the chief objects of the British Association Radio-telegraphic Committee which was appointed at Dundee in consequence of a suggestion made by him, and that as soon as the present calamitous world-war came to an end it was hoped these researches might be resumed.

\section{THE CANADIAN ARCTIC EXPEDITION.}

THE Scottish Oceanographical Laboratory, which had much to do with the oceanographical equipment of the Karluk, and especially the outfit of the Scottish contingent, consisting of Mr. James. Murray, Dr. Alastair Forbes Mackay, and Mr. W. L. McKinlay, is in receipt of a considerable amount of official and private information concerning the Canadian Arctic Expedition. The expedition was hurried in its preparation and late in its departure, and the plans were "still pretty fluid" on July 2 I, 1913. On August 5 the Karluk was beset in $145^{\circ}$ W., and drifted west to Colville River by September 7, and remained there until September 20 , when she was blown adrift by a gale. Stefánsson and a party were ashore hunting on September 19, and were thus stranded. The Karluk drove north and west past Cape Barrow until she reached $73^{\circ} \mathrm{N}$., I $62^{\circ}$ E. ; then she drove southwest and west until, on January ro last, she was crushed and sank in $3^{8}$ fathoms sixty miles north by east of Herald Island. She drifted eight hundred miles at a rate of seven miles an hour. A perilous escape was made to Wrangell Island, at the heavy cost of eight lives, to which were afterwards added three more deaths on Wrangell Island, i.e. eleven in all.

This death-roll includes all the scientific staff except Mr. W. L. McKinlay, of Glasgow, a former assistant to Dr. W. S. Bruce. The other scientific workers missing or dead are Mr. James Murray, of Glasgow, late biologist of the Scottish Loch Survey, naturalist to the first Shackleton expedition, and worker upon the Scotia invertebrates; Dr. A. Forbes Mackay, of Edinburgh, who had had wide experience in many. spheres of active life, including the Royal Navy, the South African War, and was member of the party that first ascended Mount Erebus, as well as that which reached the south magnetic pole under the leadership of Prof. David; Mr. Beauchat, anthropologist; Mr. Bjorn Mamen, topographer; and Mr. G. Malloch, geologist. Besides these, Mate Anderson. Second Mate Barker, and four seamen have also perished. Captain Bartlett, of North Pole fame, with an Eskimo, made an escape with difficulty from Wrangell Island to the mainland of Siberia, and there, with the help of the Russian Governor, Baron NO. $235 \mathrm{I}$, VOL. 94] 